\title{
Early age behaviour of recycled concrete aggregates under normal and severe drying conditions
}

Jean-Claude Souche ${ }^{1}$, Ahmed Z. Bendimerad ${ }^{2}$, Emmanuel Roziere ${ }^{2}$, Marie Salgues ${ }^{1}$, Philippe Devillers $^{3}$, Eric Garcia-Diaz ${ }^{1}$, Ahmed Loukili ${ }^{2, *}$

${ }^{1}$ Ecole des Mines d'Alès, Centre des Matériaux des Mines d'Alès (C2MA) 6 avenue de Clavières, 30319 Alès, France

${ }^{2}$ Ecole Centrale de Nantes, Civil engineering and Mechanics research Institute (GeM) - UMR CNRS 6183, 1 rue de la Noé, 44321 Nantes, France

${ }^{3}$ Ecole Nationale Supérieure d'Architecture de Montpellier, 179 rue de l'Espérou 34093 Montpellier cedex 05 (ENSAM)

\begin{abstract}
The use of recycled aggregates in concrete mixtures is a part of waste recovery strategy. The French national project RECYBETON aims at developing scientific knowledge to facilitate the use of recycled aggregates into concrete. In this experimental study, two exposure conditions were combined to analyse the behaviour of fresh and hardening concrete in standard and severe drying conditions ( $8 \mathrm{~m} . \mathrm{s}^{-1}$ wind speed). High evaporation rate promotes the development of plastic shrinkage and cracking of fresh concrete. The influence of recycled concrete aggregates proportion and initial water saturation rate were investigated. Two series of concrete mixtures were designed to reach two strength classes. The strains and weight loss of concrete samples were monitored until the stabilization of plastic shrinkage. The increase in evaporation rate accelerated the development and increased the maximum value of plastic shrinkage but did not significantly influence the shrinkageto-weight loss ratios. In severe conditions plastic shrinkage developed before initial setting thus reached higher magnitudes. The main mix-design parameter affecting the shrinkage-to-weight loss ratio and cracking was the total water-to-binder ratio. The total water content includes the water added and the water used to pre-saturate the aggregates. High evaporation rate triggered the release of water initially absorbed by recycled concrete aggregates.
\end{abstract}

\section{Keywords:}

Recycled Concrete, Plastic Shrinkage, Severe Drying, Cracking, Fresh concrete, Evaporation rate

"This is an Accepted Manuscript of an article published by Journal of Building Engineering volume 13 on Sept 2017 available online: https://doi.org/10.1016/j.jobe.2017.08.007."”

\section{Introduction}

Concrete is the most widely used material in the world. The production of concrete causes the extraction of huge amount of natural resources. Aggregates are the main part as they represent $70 \%$ of concrete volume. Sand and coarse aggregates are generally extracted locally due to the relatively high transportation costs. In several countries and regions it is more and more difficult to provide concrete producers with good aggregates while complying with environmental regulations. As construction and deconstruction often occur in the same areas, recycled concrete aggregates are expected to be more and more widely used [1].

The influence of recycled concrete aggregates (RCA) on the properties of recycled concrete has already been widely studied. The variability of recycled concrete properties is influenced by RCA, since the properties of initial concrete significantly vary. Recycled concrete has been found to show

\footnotetext{
* Corresponding author
} 
lower strength and elastic modulus, and higher shrinkage [2] [3] [4] [5] [6]. In conventional concrete, a higher water-to-cement ratio generally implies a higher drying shrinkage magnitude [7] [8] [9]. In concretes with porous aggregates, the water contained within these aggregates also plays an important role in the development of shrinkage strain [8] [10] [11]. The water released by porous aggregates is likely to induce different behaviors in drying or sealed conditions. The drying shrinkage has actually been found to increase for low-quality recycled aggregates [12] [13], as drying aggregates show shrinkage themselves [14]. In sealed conditions, the use of recycled concrete aggregates resulted in lower shrinkage aggregates [12] [13] [15]. As autogenous deformation is due to self-desiccation [16], saturated recycled aggregates could actually mitigate shrinkage by water desorption mechanism and provide an internal curing [8] [15] [17].

RCA actually show significantly higher porosity than natural aggregates [18] [19]. The higher porosity of recycled aggregates leads to higher water absorption, especially during the concrete mixing [20] [21]. The porosity of aggregates is generally expressed as the coefficient of water absorption at 24 hours, defined in standards [22]. According to European standard on specification and production of concrete [23], the total water content is the added water plus water already contained in the aggregates. The effective water content $\left(\mathrm{W}_{\text {eff }}\right)$ is the difference between the total water present in the fresh concrete and the water absorbed by the aggregates. $\mathrm{W}_{\text {eff }}$ is the water content taken into account to define the water-to-cement ratio and recommendations for limiting values of concrete compositions. Using the effective water concept, it is theoretically possible to keep the water-to-cement constant using porous aggregates with variable initial water saturation and using appropriate quantity of added water content. However experimental studies have shown that the mechanical properties and the cracking sensitivity of concrete are significantly influenced by the initial water saturation of aggregates [11] [21] [24] [25].

Plastic shrinkage occurs when the evaporation rate exceeds the bleeding rate [7] [26]. Plastic shrinkage cracking spreads when the surface tension increases due to the development of menisci in the pores which implies the increase of the capillary pore stress [27] [28]. Plastic shrinkage depends on water-to-binder (W/B) ratio and cement fineness [29]. An increase in cement fineness and a decrease in W/B ratio led to a decrease in the bleeding rate and an increase the capillary tension level [30]. Plastic shrinkage strain is reduced when the evaporated water is replaced by bleeding water, which could be provided by saturated recycled concrete aggregates [31].

Thus accelerated drying of fresh concrete is likely to increase plastic shrinkage [32] [33]. Cracking of concrete generally occurs when several parameters simultaneously lead to an increase in cracking sensitivity [34]. Mix-design parameters and boundary conditions are often associated. Very few results can be found in literature about the influence of recycled concrete aggregates on plastic shrinkage and cracking.

The present experimental study aims at assessing the plastic shrinkage of recycled concrete in severe conditions, i.e. when the evaporation rate is high and when the aggregates are initially partially saturated. Two series of concretes were studied: C 25/30 and C 35/45 strength classes. Concrete mixtures were designed varying the initial water saturation of recycled aggregates, the total water-to-binder ratio (W/B), and the rate of substitution of natural aggregates by coarse recycled concrete aggregates. Plastic shrinkage measurements were associated with other experimental techniques to understand the evolution of plastic shrinkage and the influence of recycled aggregates.

Two series of concrete mixtures were designed keeping effective water or added water contents constant. Fresh concrete was exposed to standard and severe drying conditions. The properties of the concrete mixtures with different initial water saturation and proportion of recycled aggregates under standard and severe drying conditions are analysed and discussed in this paper. 


\section{Experimental program}

\subsection{Testing program}

Two series of concrete mixtures have been studied: one for building applications called B and one for civil engineering applications called CE. They were designed with different total water-tobinder ratios (W/B) in order to reach $\mathrm{C} 25 / 30$ and $\mathrm{C} 35 / 45$ strength class [1]. Concrete mixtures were designed varying the water-to-binder ratio, the proportion of recycled concrete aggregates (RCA), and the initial water saturation of recycled concrete aggregates.

The samples were tested under normal drying conditions, "exposure 1", or under severe drying conditions, "exposure 2", that is to say under wind (Table 1). In exposure 1, effective water was kept constant. In exposure 2, added water was kept constant.

For example, a building concrete (B) in exposure 1 with natural sand ( $0 \%$ of recycled sand) and recycled coarse aggregates (100\% of recycled concrete aggregates, $\mathrm{RCA}$ ) pre-saturated at $1.2 \mathrm{~A}$ is named: 1-BR1.2A. " $\mathrm{A}$ " is the initial water saturation of aggregates corresponding to the coefficient of water absorption measured at 24 hours (NF EN 1097-6) for dried in surface aggregates state (SSD state). All studied concretes are detailed in Table 2.

Table 1. Exposure conditions

\begin{tabular}{|c|c|c|c|c|}
\hline & \multicolumn{2}{|c|}{$\begin{array}{c}\text { Exposure 1 } \\
\text { Standard drying }\end{array}$} & \multicolumn{2}{c|}{$\begin{array}{c}\text { Exposure 2 } \\
\text { Severe drying }\end{array}$} \\
\hline Concrete family & $\mathrm{B}$ & $\mathrm{CE}$ & $\mathrm{B}$ & $\mathrm{CE}$ \\
\hline $\mathrm{RH}(\%)$ & 50 & 50 & 45 & 45 \\
\hline Temperature $\left({ }^{\circ} \mathrm{C}\right)$ & 20 & 20 & 21 & 21 \\
\hline Wind $(\mathrm{m} / \mathrm{s})$ & $<0.3$ & $<0.3$ & $\mathbf{8}$ & $\mathbf{8}$ \\
\hline
\end{tabular}

Table 2. Testing program

\begin{tabular}{|c|c|c|}
\hline & \multicolumn{2}{|c|}{ Initial water saturation of recycled concrete aggregates } \\
\hline & $\mathbf{0 . 5 A}$ & $\mathbf{1 . 2 A}$ \\
\hline \multirow{2}{*}{$0 \%$ RCA } & & $1-\mathrm{BN} / 2-\mathrm{BN}$ \\
& & $1-\mathrm{CEN} / 2-\mathrm{CEN}$ \\
\hline \multirow{2}{*}{$100 \%$ RCA } & $2-\mathrm{BR}_{0.5 \mathrm{~A}}$ & $1-\mathrm{BR}_{1.2 \mathrm{~A}} / 2-\mathrm{BR}_{1.2 \mathrm{~A}}$ \\
& $2-\mathrm{CER}_{0.5 \mathrm{~A}}$ & $1-\mathrm{CER}_{1.2 \mathrm{~A}} / 2-\mathrm{CER}_{1.2 \mathrm{~A}}$ \\
\hline
\end{tabular}

\subsection{Water}

The water absorption of aggregates is a key parameter in concrete mix design. Moreover, aggregates can be partially or totally saturated when concrete is mixed. This initial water saturation of aggregates influences the early-age as well as long-term behaviour of concrete. Thus, the use of recycled aggregates in concrete modifies the available water in time. To clarify these water exchanges into fresh concrete, some notions are required.

First, the pre-saturation water $\left(\mathrm{W}_{\mathrm{ps}}\right)$ corresponds to the amount of water in the aggregates before mixing. The additional water $\left(\mathrm{W}_{\mathrm{ad}}\right)$ is the complementary water introduced in the mixer. The absorption water $\left(\mathrm{W}_{\mathrm{abs}}\right)$ is the water corresponding to saturated aggregates at nominal absorption (SSD state). The water remaining in cement paste is called the effective water $\left(\mathrm{W}_{\text {eff }}\right)$. The total water $\left(\mathrm{W}_{\text {tot }}\right)$ introduced in the mix is given by equation 1 . 


$$
W_{t o t}=W_{a b s}(A)+W_{e f f}=W_{p s}+W_{a d}
$$

In this paper, the $1.2 \mathrm{~A}$ concretes have been made with aggregates at $120 \%$ SSD initial water saturation, which means a pre-saturation degree corresponding to the nominal absorption plus approximately $1 \%$ of dry mass of aggregates.

Two test programs have been conducted:

The first one deals with tests under standard conditions.

The trials have been done with a constant effective water $\left(\mathrm{W}_{\text {eff }}\right)$; additional water varied as a function of presaturation water, balancing the theoretical aggregate absorption [35].

The second one deals with tests under severe conditions.

It has been chosen to work with constant additional water $\left(\mathrm{W}_{\mathrm{ad}}\right)$ to observe the effect of aggregates water absorption in concrete [24].

\subsection{Raw materials and concrete mix-design}

The recycled aggregates used in this study were provided by the French National Project RECYBETON [1]. They had a relatively high coefficient of water absorption, from 5.6 to $5.8 \%$ for $4 / 10$ and $10 / 20$ fractions [36].

The test results on the physical properties of natural and recycled aggregates, such as maximum size, specific gravity and water absorption are given in Table 3. Figure 1 also shows the particle distribution of fine and coarse aggregates.

Table 3. Properties of aggregates

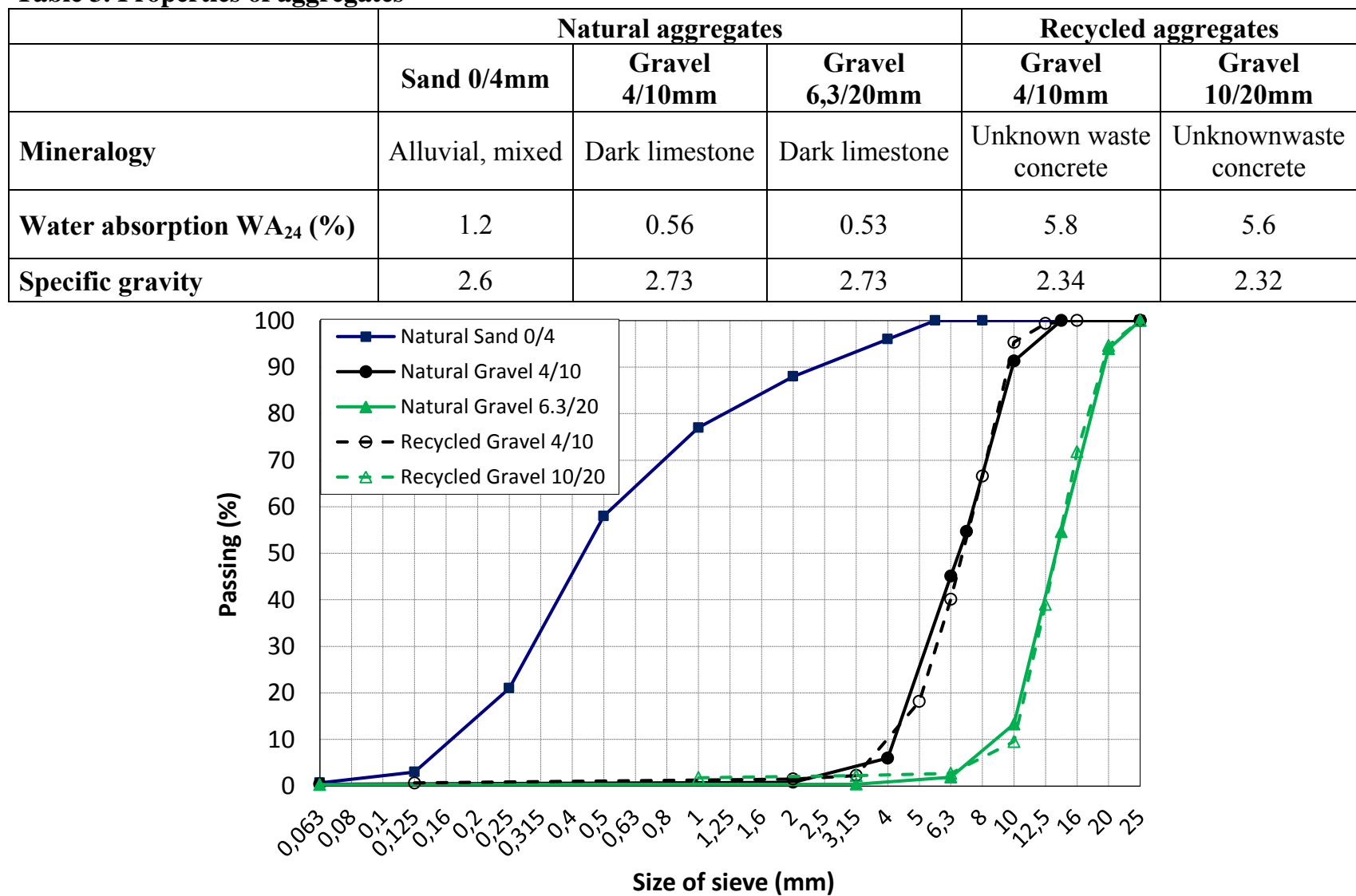

Figure 1. Particle size distributions of natural and recycled aggregates

All the concrete mixtures were made of the same batch of Portland cement CEM II/A-L 42.5 N from Rochefort in France. The cement had an estimated Bogue composition of $61 \% \mathrm{C}_{3} \mathrm{~S}, 0 \% \mathrm{C}_{2} \mathrm{~S}$, $7.9 \% \mathrm{C}_{3} \mathrm{~A}, 12 \% \mathrm{C}_{4} \mathrm{AF}$, and $\mathrm{Na}_{2} \mathrm{Oeq}$ of $0.59 \%$, a Blaine fineness of $370 \mathrm{~m}^{2} / \mathrm{kg}$ and a density of 3.09 $\mathrm{kg} / \mathrm{m}^{3}$. 
Limestone filler was taken into account into Binder content (B), defined as the sum of cement and limestone filler contents (in $\mathrm{kg} / \mathrm{m}^{3}$ ). The tested concrete mixtures were designed within the National Project RECYBETON. Their composition and compressive strength are detailed in Tables 4 and 5. Concrete mixtures given in Table 4 were reference mixtures. They were studied under normal drying conditions "exposure 1". Two sets of concrete mixtures were designed to reach two strength classes (C25/30 and C35/45). Thus it was necessary to increase the cement contents of concrete mixtures with RCA to reach the same strength and slump as corresponding concrete mixtures with natural aggregates. However $\mathrm{CER}_{1.2 \mathrm{~A}}$ concrete did not reach $35 \mathrm{MPa}$ strength in this study.

The mixtures given in Table 5 were studied under severe drying conditions "exposure 2". In this part of the study the concrete mixtures with RCA in order to show the effect of initial saturation of RCA on plastic shrinkage and cracking. A previous experimental study [37] showed that plastic shrinkage is not significantly influenced by RCA initial saturation if this is compensated by added water, which means that total water content is kept constant. In this study, the added water was the same whatever the initial saturation of RCA (1.2 A or $0.5 \mathrm{~A})$, thus total water content varied (Table 5). The lower the initial saturation, the lower the water-to-binder ratio, and the higher the strength was.

Table 4. Building (B) and Civil engineering (CE) concrete mixtures tested under exposure 1.

\begin{tabular}{|c|c|c|c|c|}
\hline Constituents $\left(\mathrm{Kg} / \mathrm{m}^{3}\right)$ & $\underset{m}{Z}$ & $\frac{\mathbb{I}}{\stackrel{\mathbb{c}}{\underline{n}}}$ & 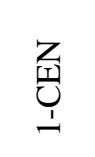 & 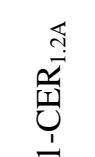 \\
\hline $\begin{array}{c}\text { Cement }(\mathrm{C}) \\
\text { CEM II/A-L 42,5 N }\end{array}$ & 270 & 282 & 299 & 336 \\
\hline Limestone filler (L) & 45 & 31 & 58 & 53 \\
\hline Sand $0 / 4$ & 780 & 806 & 771 & 782 \\
\hline Gravel 4/10 & 267 & - & 264 & - \\
\hline Recycled gravel 4/10 & - & 163 & - & 158 \\
\hline Gravel 6,3/20 & 820 & - & 810 & \\
\hline Recycled gravels $10 / 20$ & - & 701 & - & 682 \\
\hline Superplasticizer & 0.75 & 0.80 & 1.26 & 1.31 \\
\hline Initial effective water $\left(\mathrm{W}_{\mathrm{eff}}\right)$ & 180 & 189 & 175 & 185 \\
\hline $\mathrm{W}_{\text {eff }} / \mathrm{B}$ & 0.57 & 0.60 & 0.49 & 0.48 \\
\hline Pre-saturation water of recycled gravel $4 / 10$ & - & 10.4 & - & 10.1 \\
\hline Pre-saturation water of recycled gravel 10/20 & - & 41.1 & - & 40.0 \\
\hline Total water $(\mathrm{W})$ & 194.6 & 241.0 & 188.7 & 235.1 \\
\hline $\mathrm{W} / \mathrm{B}$ & 0.62 & 0.77 & 0.53 & 0.60 \\
\hline Paste proportion $(\%)$ & 29.3 & 30 & 30.2 & 32.1 \\
\hline Slump test values $(\mathrm{cm})$ & 19.4 & 19.7 & 21 & 21.6 \\
\hline $\begin{array}{c}\text { Compressive strength ( } 28 \text { days) } \\
\text { Average values }(\mathrm{MPa})\end{array}$ & 31.4 & 28.8 & 38.3 & 32.9 \\
\hline
\end{tabular}


Table 5. Building (B) and Civil engineering (CE) concrete mixtures tested under exposure 2

\begin{tabular}{|c|c|c|c|c|c|c|}
\hline Constituents $\left(\mathrm{Kg} / \mathrm{m}^{3}\right)$ & $\begin{array}{l}Z \\
\text { ì } \\
\text { c }\end{array}$ & 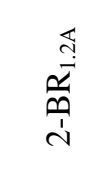 & 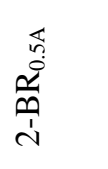 & 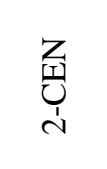 & 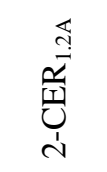 & 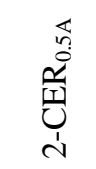 \\
\hline $\begin{array}{l}\text { Holcim cement (C) } \\
\text { CEM II/A-L 42,5 N }\end{array}$ & 270 & 282 & 282 & 299 & 336 & 336 \\
\hline Limestone filler $(\mathrm{L})$ & 45 & 31 & 31 & 58 & 53 & 53 \\
\hline Sand $0 / 4$ & 780 & 806 & 806 & 771 & 782 & 782 \\
\hline Gravel 4/10 & 266 & - & - & 264 & - & - \\
\hline Recycled gravel 4/10 & - & 163 & 163 & - & 158 & 158 \\
\hline Gravel 6,3/20 & 820 & - & - & 810 & - & - \\
\hline Recycled gravels 10/20 & - & 701 & 701 & - & 682 & 682 \\
\hline Superplasticizer & 1.35 & 1.40 & 1.40 & 2.10 & 2.18 & 2.18 \\
\hline Initial effective water $\left(\mathrm{W}_{\text {eff }}\right)$ & 166 & 174 & 174 & 151 & 156.8 & 156.8 \\
\hline $\mathrm{W}_{\text {eff }} / \mathrm{B}$ & 0.53 & 0.56 & 0.56 & 0.42 & 0.40 & 0.40 \\
\hline Pre-saturation water of recycled gravel $4 / 10$ & - & 10.76 & 4.56 & - & 10.43 & 4.42 \\
\hline Pre-saturation water of recycled gravel 10/20 & - & 47.67 & 20.33 & - & 46.38 & 19.78 \\
\hline Total water $(\mathrm{W})$ & 180.1 & 232 & 207.1 & 164.9 & 213 & 188.8 \\
\hline $\mathrm{W} / \mathrm{B}$ & 0.57 & 0.74 & 0.66 & 0.46 & 0.55 & 0.49 \\
\hline Paste proportion $(\%)$ & 29.3 & 30.8 & 29.8 & 29.7 & 32.1 & 30.9 \\
\hline Slump test values $(\mathrm{cm})$ & 19 & 21 & 18 & 19.5 & 20 & 17 \\
\hline $\begin{array}{c}\text { Compressive strength ( } 28 \text { days) } \\
\text { Average values }(\mathrm{MPa})\end{array}$ & 31.4 & 23.6 & 26.7 & 40.1 & 36.9 & 42.8 \\
\hline
\end{tabular}

\subsection{Testing procedures}

The tests started $20 \mathrm{~min}$ after the first contact between water and cement into the mixer. For all curves, the origin of time is the beginning of drying.

2.4.1 Standard conditions

Plastic shrinkage was measured in an air-conditioned room at $20^{\circ} \mathrm{C}$ constant temperature and $50 \%$ relative humidity. The velocity of wind was lower than $0.3 \mathrm{~m} / \mathrm{s}$.

Two identical prismatic moulds $\left(70 \times 70 \times 280 \mathrm{~mm}^{3}\right)$ were used for each test. They are made of steel plates covered with Polytetrafluoroethylene (PTFE) on their inner face to limit friction with specimen. The temperature of the mould is controlled using temperature controlled water circulating in the horizontal and vertical plates. Each concrete sample is poured in a flexible mould made of a plastic sheet and two PVC plates $\left(70 \times 68 \times 5 \mathrm{~mm}^{3}\right)$ anchored to both ends of the sample. 
The PVC plates are used as reflectors for laser sensors (Figure 2). The accuracy of the laser sensors is $2 \mu \mathrm{m}$. The actual concrete temperature is monitored using a thermocouple placed in the centre of the sample [32] [35].

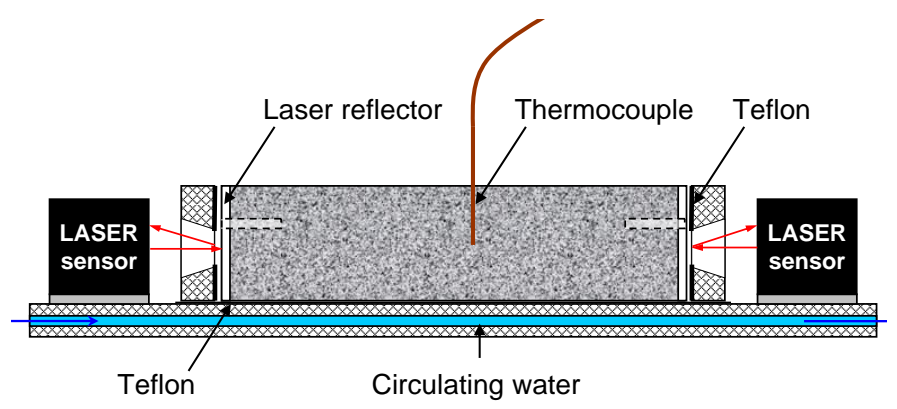

Figure 2. Plastic shrinkage measuring device.

\subsubsection{Severe conditions}

Tests were carried out in sealed conditions or under desiccation to compare the effect of test conditions on fresh concrete behaviours. Severe drying conditions refer to controlled temperature and relative humidity of $21^{\circ} \mathrm{C}$ and $45 \%$. The ventilated bench-testing (Figure 3.a) provide an uniform air circulation during the test with no disturbance to air flow (wind velocity equal to $8 \mathrm{~m} / \mathrm{s}$ or $26 \mathrm{~km} / \mathrm{h}$ ). It allows to simulate severe drying conditions [33] [24].

Measurement of shrinkage took place in a prismatic metal mold with dimensions $30 \mathrm{~cm} \mathrm{x} 30 \mathrm{~cm} \mathrm{x}$ $8,4 \mathrm{~cm}$ whose walls are coated by Teflon. The concrete was put in place using a plastic sheet (Figure 3.a). Mass loss measurements were made using cylinders $16 \mathrm{~cm}$ in diameter and $8,4 \mathrm{~cm}$ high placed on a balance (Figure 3.a). A specific cracking mould has been realized in order to observe early cracking of the concrete (Figure 3.b). The mould, inspired by standard [38], is prismatic with the following interior dimensions $56 \times 35.5 \times 8.4 \mathrm{~cm}$.

During ventilated bench testing, the initiation and the propagation of cracking is followed and recorded (Figure 3.b) from the ventilation start to the end of the test (7h later). Grundig FA 87-I photo cameras with high resolution, managed by the software Labview 7.0, are used to observe the cracking evolution in time. The tunnel temperature is regulated at $21^{\circ} \mathrm{C} \pm 2{ }^{\circ} \mathrm{C}$ and hygrometry at $45 \% \mathrm{RH} \pm 4 \%$.

In this study, the highest values of crack opening were measured using the ImageJ software. Then a characteristic value of the crack opening is considered. It is based on a fractile calculation in accordance with Eurocode 2 as explain in Equation $\mathrm{Eq}(2)$.

$$
w_{k}=\bar{x}+1,96 \frac{\sigma(x)}{\sqrt{n}}
$$

With $\mathrm{W}_{\mathrm{k}}$, the characteristic crack opening at $95 \%$ fractile, $\bar{x}$ the average crack opening value, $\sigma(x)$ the standard deviation, $\mathrm{n}$ the number of measures. 


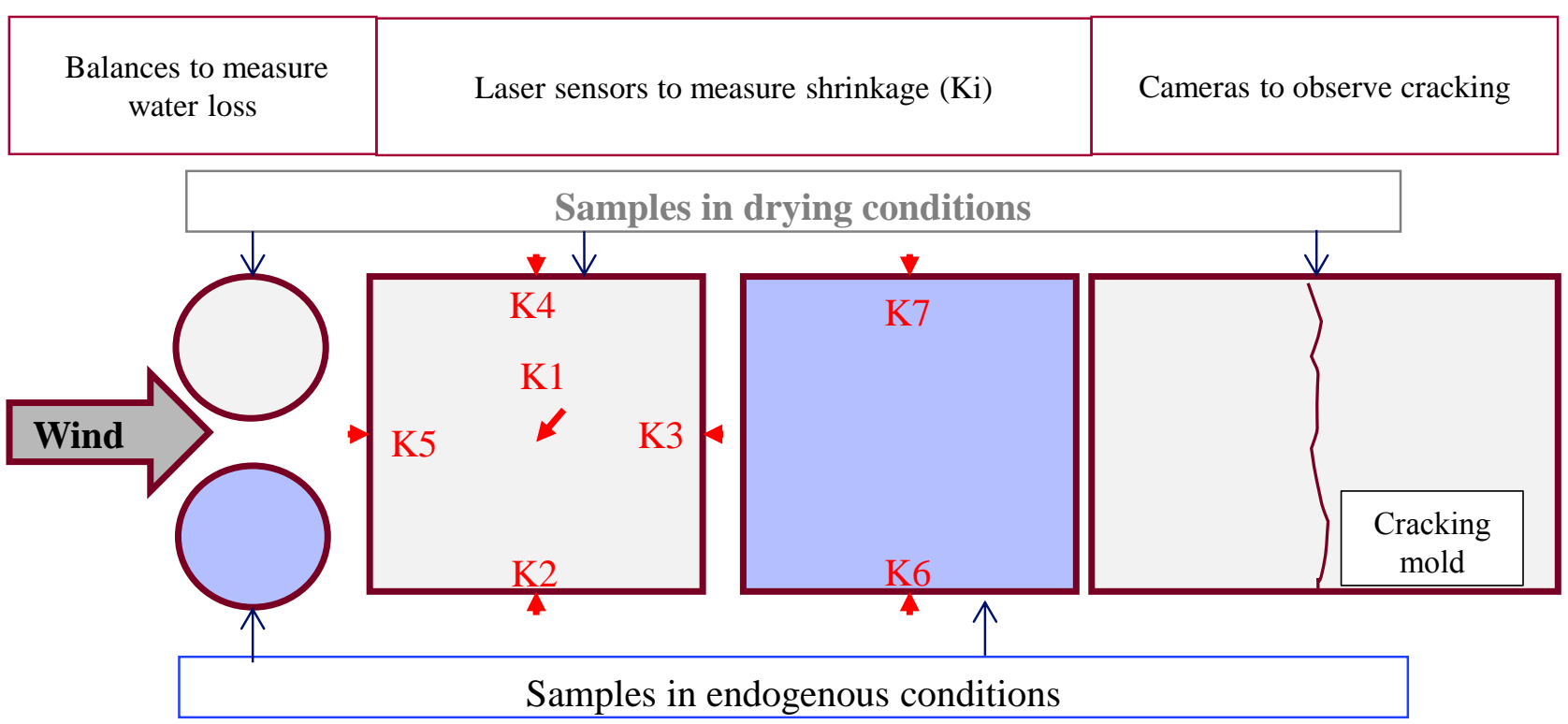

(a) Ventilated bench-testing, schematic overview

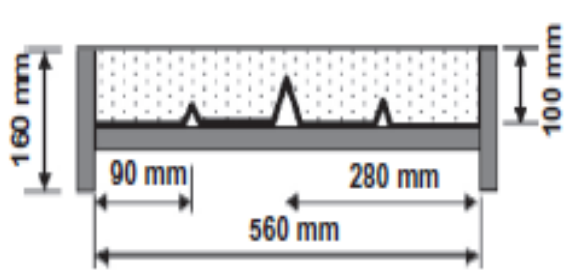

Side View

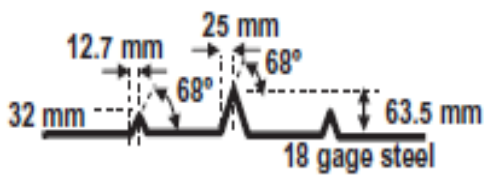

Stress Riser Geometry

(b) ASTM 1579C06 cracking mold details [39]

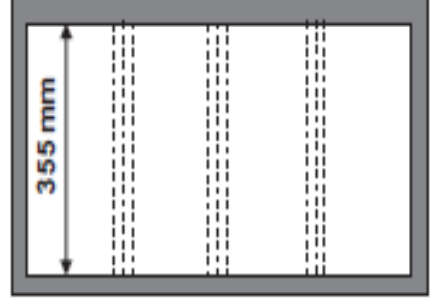

Top View

Figure 3. Ventilated bench-testingand the ASTM cracking mold.

\section{Results and discussion}

\subsection{Effect of environmental conditions}

The curves of evaporation as a function of time start with a linear section (Figure 4). The drying flux is the slope of this linear part of the curve. This first stage lasted approximately three hours under severe drying conditions and up to 8 hours under standard drying conditions. 


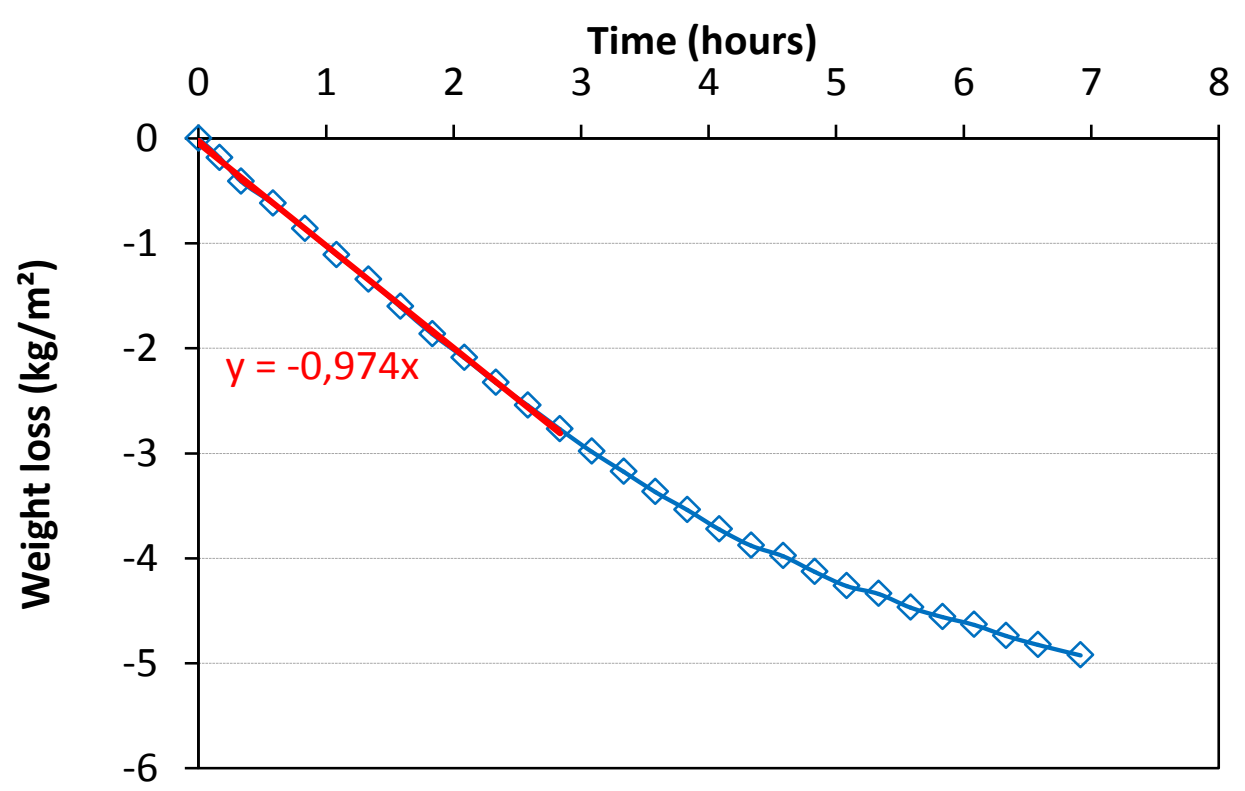

Figure 4. Drying curve for BN concrete under severe drying conditions.

The curve is consistent with drying kinetics described by [27] and [40]. At the beginning of the test, the material and air room temperatures are similar. During the first hours of the test, the water evaporates in the air with a constant flux. The top face of the material is kept saturated because of the transport of pore solution through fresh concrete. Then menisci form at the topmost surface and volume variations remain close to the volume of evaporated water. As a consequence, capillary pressure is built up in the pore system resulting in tensile forces and shrinkage [27] [41]. If the negative capillary pressure reaches "air-entry" value, air starts penetrating the pores system locally. The volume change of the sample is no longer equal to the volume of evaporated water. The settlement reaches a maximum and the horizontal strains start increasing. Then the menisci move into the material and the permeability of concrete decreases. Finally drying rate slows down [40], as the water is only located in the porous network leading to a strong reduction of the exchange surface [27].

The drying fluxes measured under standard drying conditions (exposure 1) are given in Table 6 . They were of the same order of magnitude as data from [32], [41], from 0.10 to $0.20 \mathrm{~kg} \cdot \mathrm{m}^{-2} \cdot \mathrm{h}^{-1}$. The average surface drying fluxes measured under a wind speed equal to $8 \mathrm{~m} / \mathrm{s}$, are given in Table 7 . They are in the same order of magnitude as $1 \mathrm{~kg} \cdot \mathrm{m}^{-2} \cdot \mathrm{h}^{-1}$, value calculated with [42][34].

Under severe drying conditions (exposure 2), the flux values were significantly higher. ACI report and the Canadian code nominates that precautions should be taken when the rate of evaporation exceed $1 \mathrm{~kg} / \mathrm{m}^{2} / \mathrm{h}$ and $0.75 \mathrm{~kg} / \mathrm{m}^{2} / \mathrm{h}$ respectively [43]. At this value plastic shrinkage cracking is likely to occur.

Table 6. Average surface drying flux of studied concretes from exposure 1

\begin{tabular}{|c|c|c|c|c|}
\hline $\begin{array}{c}\text { Average surface drying flux } \\
\mathrm{J}\left(\mathrm{Kg} / \mathrm{m}^{2} . \mathrm{h}\right)\end{array}$ & $1-\mathrm{BN}$ & $1-\mathrm{BR}_{1.2 \mathrm{~A}}$ & 1-CEN & 1-CER $_{1.2 \mathrm{~A}}$ \\
\hline Standard drying conditions & 0.14 & 0.16 & 0.135 & 0.12 \\
\hline
\end{tabular}

Table 7. Average surface drying flux of studied concretes from exposure 2

\begin{tabular}{|c|c|c|c|c|c|c|}
\hline $\begin{array}{c}\text { Average surface drying flux } \\
\mathrm{J}\left(\mathrm{Kg} / \mathrm{m}^{2} . \mathrm{h}\right)\end{array}$ & $2-\mathrm{BN}$ & $2-\mathrm{BR}_{1.2 \mathrm{~A}}$ & 2-BR $0.5 \mathrm{~A}$ & 2-CEN & 2-CER ${ }_{1.2 \mathrm{~A}}$ & 2-CER $_{0.5 \mathrm{~A}}$ \\
\hline Severe drying conditions & 0.97 & 1.19 & 1.08 & 0.80 & 0.87 & 0.82 \\
\hline
\end{tabular}

Bleeding water was observed at the top of the moulds for building concretes. And during the first period, due to the layer of bleed water, the evaporation rate is often considered as close to that of 
free water. However, the rate can be influenced by pore solution and concrete properties. The drying fluxes of Building concretes were from 18 to $27 \%$ higher than Civil engineering concretes which showed very few bleeding water at the top of the moulds. Building concrete mixtures actually had higher water-to-binder (W/B) ratios, thus less concentrated pore solution. During the settlement of fresh concrete, the pore solution of concrete migrates to the upper surface of the sample. The bleeding rate can be related to the permeability of fresh concrete [44]. The higher the W/B ratio, the higher the water permeability is [24] The water-to-cement ratio influence bleeding and evaporation rate [45]. The flux also depends on the permeability of the fresh concrete. The higher the permeability, the higher the drying flux is. Concretes made with RCA had slightly higher permeability [24]. Moreover RCA is able to release absorbed water, contributing to the flux of bleeding water. RCA concretes actually had higher fluxes than natural aggregates concrete in severe drying conditions. Pre-wetted lightweight aggregates (LWA) particles are able to provide water during the first hours of drying, including the plastic phase, under severe drying conditions [46]. So, the bleeding water accumulated on the top face of the sample protects concrete from desiccation. It is a natural curing process of fresh concrete if the initial W/B ratio of the concrete mixture is high enough to provide excess water.

\subsection{Shrinkage of natural and recycled concretes}

In this section the behaviours of studied natural aggregates concretes from both exposure conditions (1-BN, 2-BN, 1-CEN, 2-CEN) are first compared in order to understand the influence of environmental conditions on plastic shrinkage. Plastic shrinkage has been plotted as a function of time (Figure 5) and weight loss (Figure 6).

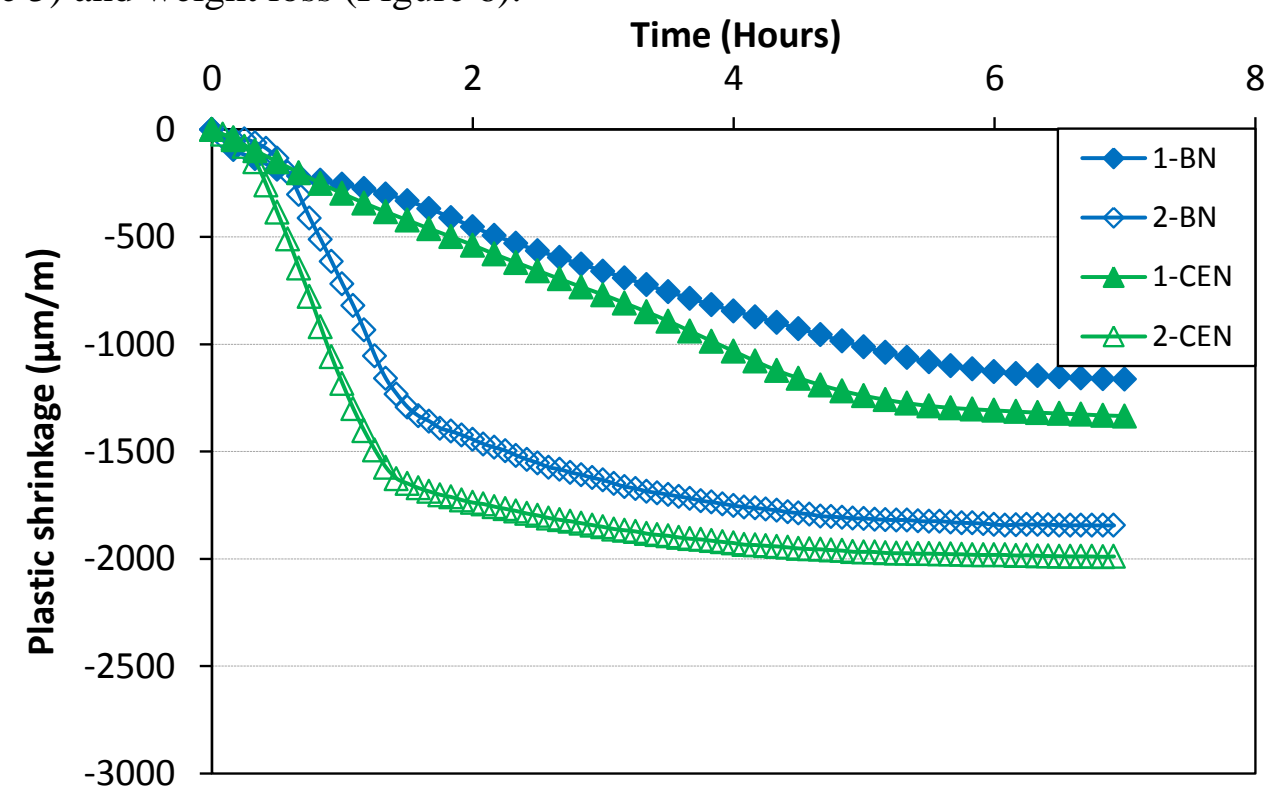

Figure 5. Plastic shrinkage versus time.

Under standard drying conditions, the shrinkage curve is quite linear from 1 to 5 hours. It reaches its maximum value, about $1100 \mu \mathrm{m} / \mathrm{m}$ for building concrete and $1300 \mu \mathrm{m} / \mathrm{m}$ for civil engineering concrete, after 7 to 8 hours. Under severe drying conditions, the shrinkage curve is linear between 0.5 and 1.5 hour. The maximum values, about $1750 \mu \mathrm{m} / \mathrm{m}$ for building concrete and $2000 \mu \mathrm{m} / \mathrm{m}$ for civil engineering concrete are reached after 4 hours. The plastic shrinkage magnitudes measured under severe conditions are in accordance with literature [32] [33] [41]. 


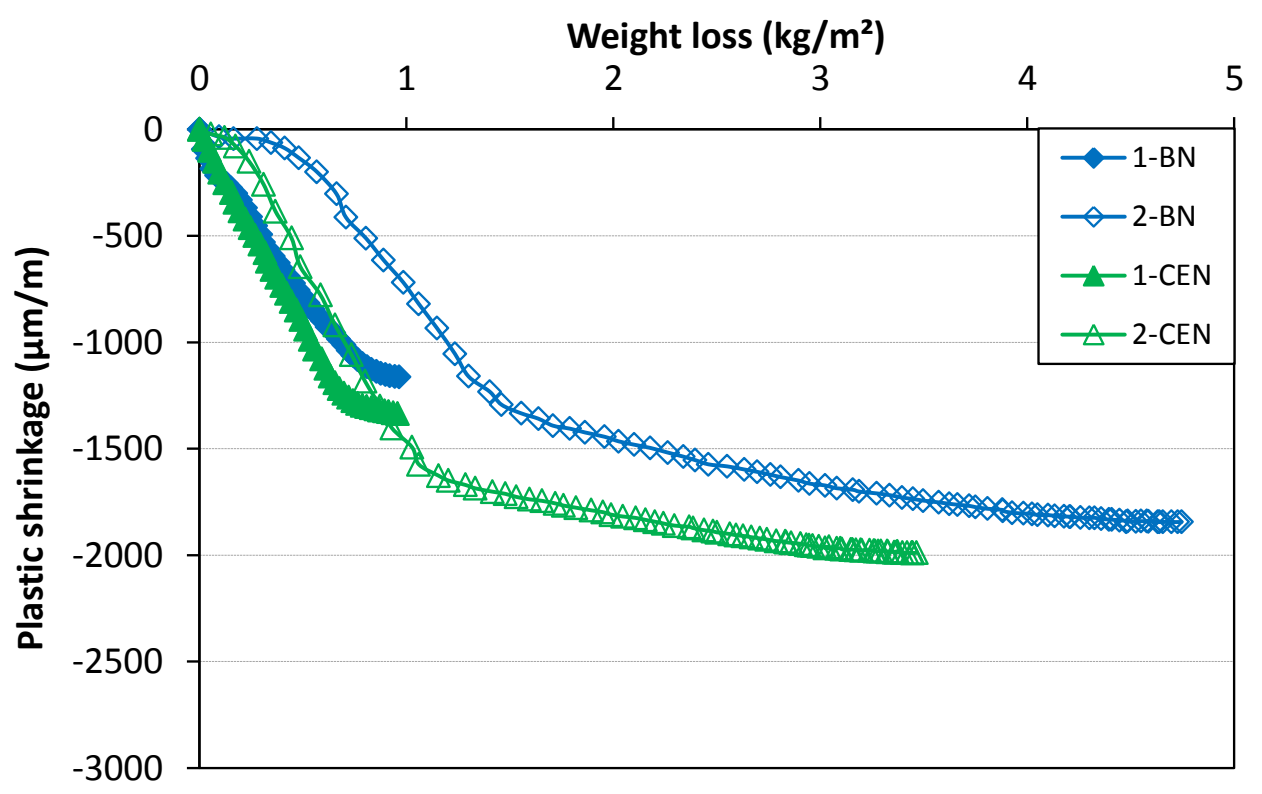

Figure 6. Plastic shrinkage versus weight loss.

The plastic shrinkage evolution plotted as a function of weight loss (Figure 6) shows similar behaviours of samples in both drying conditions. The development of plastic shrinkage was slightly delayed for concretes of exposure 2. They actually showed higher bleeding (independently from drying conditions) than concretes tested in exposure 1. Especially BN samples had significant amount bleeding water accumulated on the upper face.

Then, the second stage shows a constant shrinkage rate. The shrinkage reflects the water volume variations. The slope of the linear part of the curves was identical in both programs, for a given concrete mixture.

Finally, during the third phase, the shrinkage rate gradually decreased until the end of the test and the weight losses resulted in increasing air fraction in the pore system. The beginning of the third stage appeared at lower weight loss for concretes of exposure 1. In standard drying conditions, the decrease of plastic shrinkage rate actually occurs between initial and final setting times [19], when shear modulus became significant. The initial setting times (determined according to Vicat test) of 1-BN and 1-CEN concrete mixtures were respectively $6.7 \mathrm{~h}$ and $6.0 \mathrm{~h}$. In severe conditions, plastic shrinkage mostly developed before 2 hours. At this time the stiffness of concrete was still negligible, thus the development of plastic shrinkage was not limited and it reached higher values.

Figure 7 shows the influence of coarse aggregates proportion under standard conditions (exposure 1). During the first stage, the differences were not significant. The first stage actually corresponds to the development of settlement and bleeding. The first stage was slightly longer for concrete with RCA. These concrete mixtures were actually made of initially saturated aggregates, which could have released water in cement paste. The different behaviours were mostly revealed during the second stage. Building concretes with and without recycled concrete aggregates (BN and BR) showed lower shrinkage rate than Civil engineering concretes (CEN and CER). This means that a given water loss induced lower shrinkage strains. This could be explained by differences in pore diameters. BN and BR concrete mixtures actually had higher water-to-binder ratios than CEN and CER concrete mixtures (see Tables 4 and 5). Higher water-to-binder ratio results in coarser porosity [47] thus lower capillary pressure $\sigma_{c a p}$ according to Young Laplace (Equation 3).

$$
\sigma_{\text {cap }}=-\frac{2 \gamma \cos (\theta)}{r}
$$

Where $\gamma(\mathrm{N} / \mathrm{m})$ is the surface tension of pore fluid, $\theta$ (radians) is the liquid-solid contact angle, and $\mathrm{r}(\mathrm{m})$ is the radius of curvature of the meniscus or the pore size.

For a given strength class (B or CE), the slopes of shrinkage vs. weight loss curves did not significantly differ during the second stage. This analysis suggests that the behaviour of concrete was mainly influenced by cement paste and that RCA did not significantly dry. According to 
Kelvin-Laplace equation, when concrete is exposed to drying, as internal relative humidity decreases, large pores are dried then finer ones. RCA are actually made of old concrete with higher hydration degree and finer pores. During plastic shrinkage test, internal relative humidity of new concrete decreased but it was not low enough to empty pores of RCA. As the water-to-binder ratio was kept constant when substituting natural aggregates by RCA, both concrete mixtures lead to approximately the same behaviour. During the third stage, the shrinkage magnitudes of CE concretes were finally higher than B concretes. Concrete made of RCA showed lower plastic shrinkage magnitude than concrete with natural aggregates. This could be due to internal curing provided by initially saturated RCA. Lighweight aggregates have been shown to provide internal curing [8]. Maruyama et al. [13] and Heajin et al. [17] also showed that recycled aggregates can be used as an internal curing agent to reduce autogenous shrinkage of high strength concrete [48].

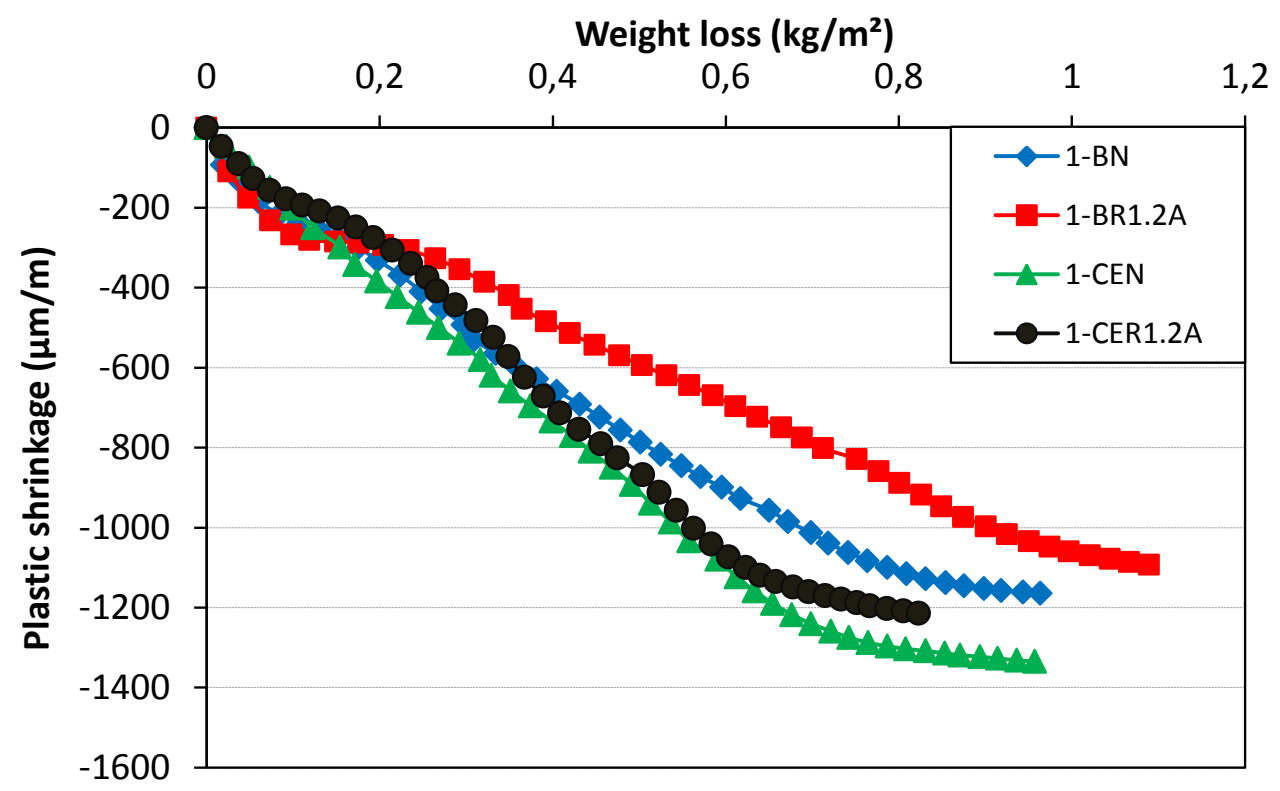

Figure 7. Influence of coarse aggregates proportion under standard conditions

Figure 8 shows the influence of coarse aggregates proportion under severe conditions. The exposure condition 2 induced more significant differences at each stage. The beginning of the second stage was delayed for concrete mixtures with RCA. This could be due to higher bleeding provided by a part of additional water of initially saturated RCA.

The second stage also showed a linear behaviour, with an equivalent (B) or higher (CE) rate for concrete with RCA. Both series of concrete showed the same behaviour with a crossing of the two curves ( $\mathrm{N}$ and $\mathrm{R}$ ) at the end of second stage. The plastic shrinkage of RCA-based concretes was finally higher than concretes with natural aggregates. Maruyama et al. [13] actually observed that the drying shrinkage of concrete made of recycled aggregate developed rapidly after removing the seal and finally exceeded the deformation of the reference concrete.

Recycled aggregate actually have fine porosity due to their old cement paste content, where menisci are likely to form and create capillary stresses when concrete is exposed to severe drying. Moreover RCA are characterised by a lower elastic modulus, thus the restraining effect of aggregates on the shrinkage of cement paste is lower and the shrinkage of the composite material increases [49]. From these results the drying of concrete in severe conditions (low relative humidity and strong wind) seems to trigger a phenomenon that could not be observed under standard drying conditions: the drying of RCA and its consequences on plastic shrinkage of new concretes. The influence of drying shrinkage of natural aggregates on drying skrinkage of concrete has been experimentally shown by Fujiwara et al. [14] Concrete shrinkage is mainly due to cement paste. As RCA are partly made of old cement paste, they are also likely to shrink when exposed to drying. Domingo-Cabo et al. [10] actually found that drying shrinkage of concrete increase with RCA proportion. 


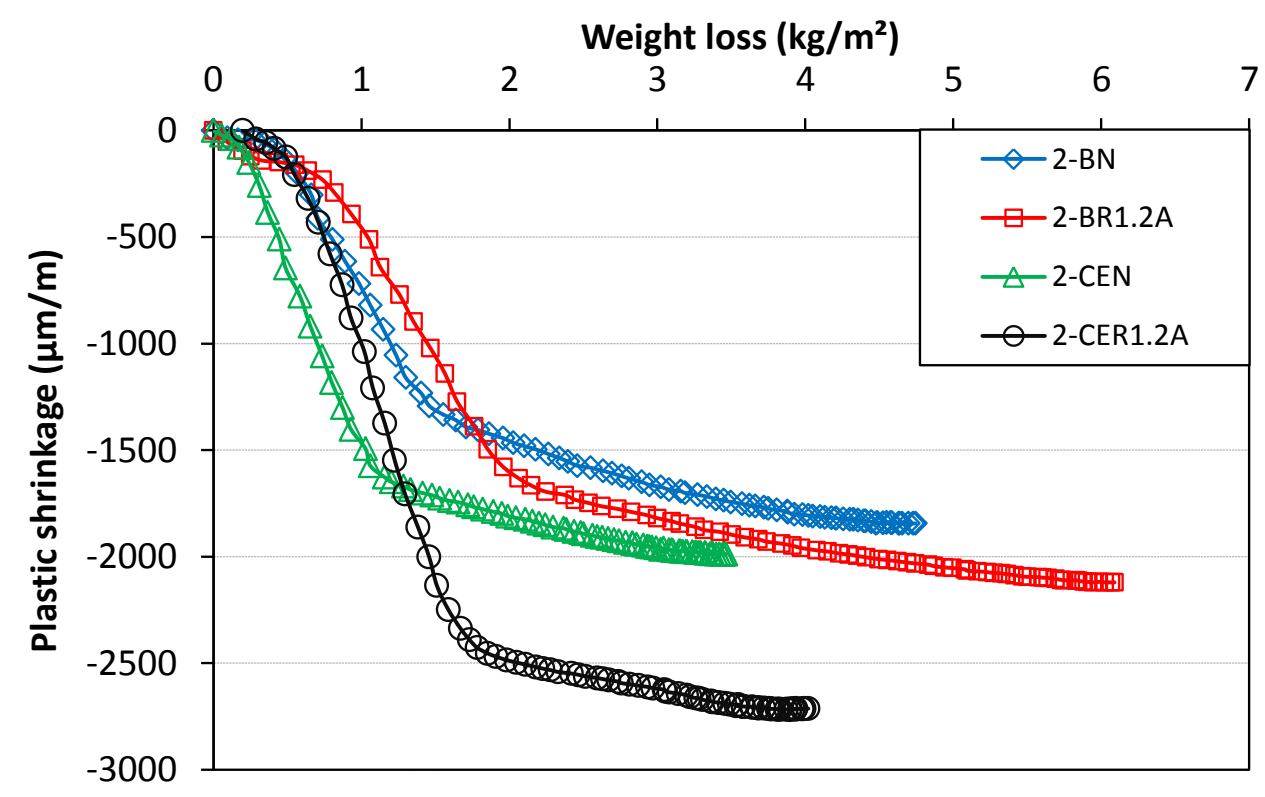

Figure 8. Influence of coarse aggregates proportion under severe conditions

Previous study included in exposure 1 showed that the plastic shrinkage of concrete with $100 \%$ RCA was weakly dependent on the initial water saturation of aggregates [37], in standard conditions. In these conditions, the velocity of wind was relatively low and the partial saturation of RCA was compensated by variable additional water content. Moreover, the recycled gravel had a high absorption rate during the first two hours thus the influence of initial water saturation of RCA was relatively low.

As a consequence, this study mainly focuses on the impact of the initial water saturation of recycled concrete aggregates under severe conditions. Fresh concrete behaviours such as early shrinkage and cracking were investigated. Two saturation degrees have been studied: $0.5 \mathrm{~A}$ and $1.2 \mathrm{~A}$ (cf. 2.2) and added water is similar for both concretes. Tests were realized with ventilated bench-testing under a wind of $8 \mathrm{~m} / \mathrm{s}$.

Figure 9 shows the influence of pre-saturation of coarse aggregates under severe drying conditions (exposure 2). During the first stage, the differences between Building concretes and Civil engineering concretes were not significant because of bleeding water on the top face of the samples. The different behaviours were revealed during the second stage when the development of the capillary pressure begins. Building concretes showed lower shrinkage rate than Civil engineering concretes although the drying flux was higher for Building concretes. This means that a given water loss induced higher shrinkage strains for $\mathrm{CER}_{0.5 \mathrm{~A}}$ and $\mathrm{CER}_{1.2 \mathrm{~A}}$ than for $\mathrm{BR}_{0.5 \mathrm{~A}}$ and $\mathrm{BR}_{1.2 \mathrm{~A}}$. This could be explained by differences in permeability, in water-to-binder ratios, in total water quantity and in bleeding water quantity. For a given strength class (B or CE), the slopes of shrinkage vs. weight loss curves were similar. 


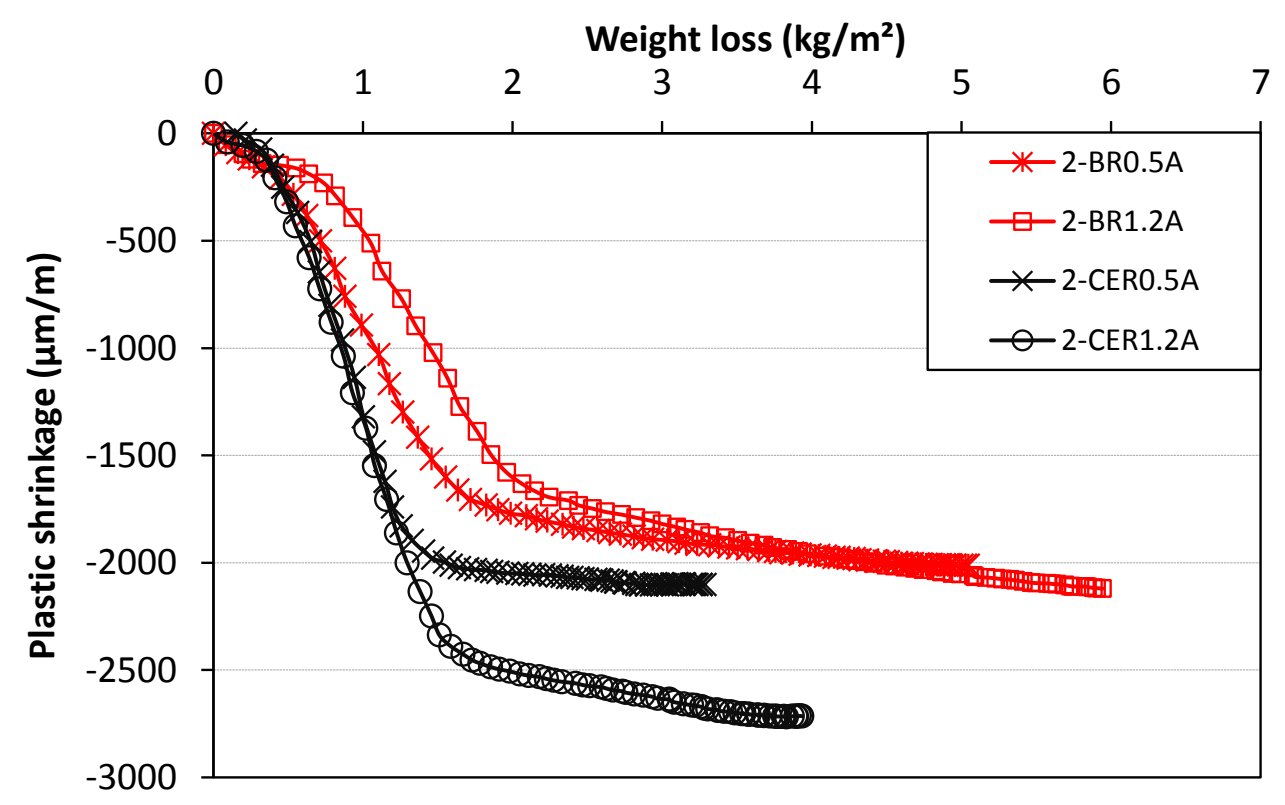

Figure 9. Horizontal shrinkage of RCA concrete under severe conditions

Concrete shrinkage values at the end of the test are reported in Table 8. 1.2A fully pre-saturated recycled concretes showed a higher shrinkage than partially presaturated concrete $0.5 \mathrm{~A}$. This trend was stronger for civil engineering concretes $(+30 \%)$. Moreover, $1.2 \mathrm{~A}$ civil engineering concretes had higher shrinkage $(+27 \%)$ than $1.2 \mathrm{~A}$ building concretes.

Table 8. Concrete shrinkage values (average value on two tests) at the end of the test ( $7.2 \mathrm{~h}$ )

\begin{tabular}{|c|c|c|c|c|}
\hline & $2-\mathrm{BR}_{1.2 \mathrm{~A}}$ & $2-\mathrm{BR}_{0.5 \mathrm{~A}}$ & $2-\mathrm{CER}_{1.2 \mathrm{~A}}$ & 2-CER $\mathrm{CE.5A}$ \\
\hline $\begin{array}{c}\text { Concrete shrinkage } \\
\text { at } 7.2 \mathrm{~h}(\mu \mathrm{m} / \mathrm{m})\end{array}$ & 2125 & 1995 & 2713 & 2082 \\
\hline
\end{tabular}

Figure 10 gives all the slopes of shrinkage vs. weight loss curves during the constant rate period. The values were around $1200 \mu \mathrm{m} . \mathrm{m}_{\mathrm{kg}}{ }^{-1}$ for Building concretes and $2000 \mu \mathrm{m} . \mathrm{m} . \mathrm{kg}^{-1}$ for Civil engineering concretes.

For a given concrete mixture, under standard or severe drying conditions, the slope values were of the same order of magnitude. According to this analysis, the main parameter was the strength class, in other words the water-to-binder ratio and to a lower extent the volume of paste (Tables 4 and 5).

The influence of RCA was found to depend on the strength class. 1-BR ${ }_{1.2 \mathrm{~A}}$ and 2-BR $\mathrm{BR}_{1.2 \mathrm{~A}}$ concretes actually showed lower values than corresponding BN concretes, whereas 1-CER $1.2 \mathrm{~A}$ and $2-\mathrm{CER}_{1.2 \mathrm{~A}}$ showed higher values than corresponding CEN concretes. This could be explained by the mixdesign. All the Building concrete mixtures had approximately the same $\mathrm{W}_{\text {eff }} / \mathrm{B}$ ratio and volume of paste, whereas it was necessary to reduce the $\mathrm{W}_{\text {eff }} / \mathrm{B}$ ratio and increase the volume of paste of CER concretes to reach the $\mathrm{C} 35 / 45$ strength class. This resulted in higher values of plastic shrinkage to weight loss ratios. 


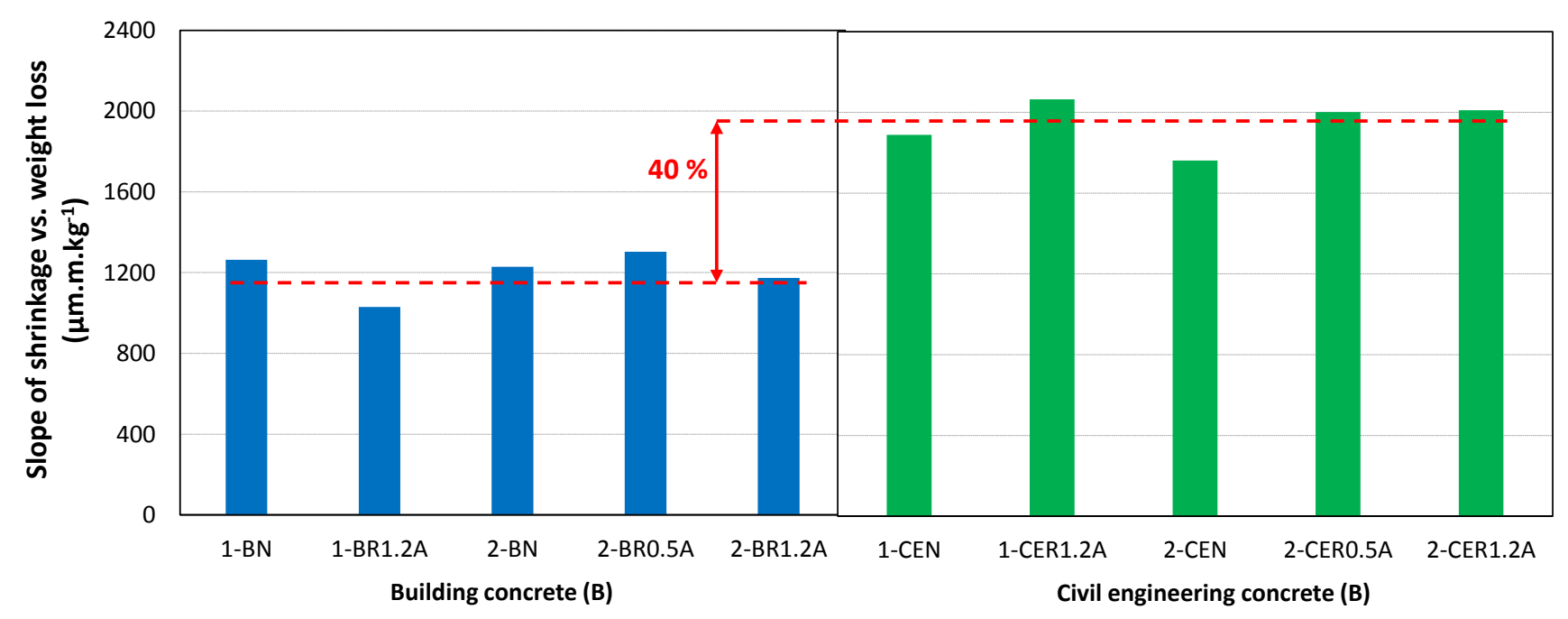

Figure 10. Slope of the linear part of plastic shrinkage vs. weight loss curves.

Under standard drying conditions, the drying flux was almost similar for all concretes. Severe conditions did not result in higher plastic shrinkage to weight loss ratios, but they significantly influenced the magnitude of plastic shrinkage. At high evaporation rates the development of plastic shrinkage was accelerated thus it could develop before initial setting time, which was not possible in standard drying conditions (Figures 5 and 6).

Figure 11 shows correlations between plastic shrinkage value at 7.2 hours and W/B ratio. This graph shows decreasing magnitudes under standard conditions and increasing shrinkage magnitudes under severe drying conditions.

In standard drying conditions, plastic shrinkage decreased with W/B ratio. According to its definition [7] [26] plastic shrinkage develops when the evaporation exceeds the bleeding rate. Other studies confirmed that shrinkage does not develop as long as bleed water prevents the formation of menisci in the top layer [28]. Concrete mixtures with higher W/B ratio are actually characterized by a highest settlement and bleeding rate [32] [45]. Bleeding water provides concrete with a natural protection (self-curing) against evaporation and mitigates plastic shrinkage. Leeman et al. [39] showed that bleeding delays the decrease in capillary pressure. Thus Building concretes showed lower shrinkage rate than civil engineering concretes in spite of higher drying flux for building concretes. Kai et al. [30] found that an increase in cement surface area resulted in lower evaporation rate but higher plastic shrinkage. Slowik et al. [29] also showed that early age cracking risk increases with decreasing particle sizes. Finer cement particles and lower W/C concrete actually lead to reduced bleeding rates and increased capillary pressures. Concrete mixtures with RCA led to lower plastic shrinkage than corresponding concretes with natural aggregates. They actually benefited from higher W/B ratio (self-curing), and water released by RCA. Gonzalez et al. [12] found higher plastic shrinkage for high-performance concrete with RCA. However they studied concrete mixtures with significantly lower W/B of 0.29 . In another study [31] at higher W/B of 0.45 , the same authors actually found that RCA mitigated plastic shrinkage. These concretes have a higher total water amount due to initially saturated RCA, which favours bleeding.

For Building concretes under severe drying conditions, the fluxes were of the same order of magnitude and the shrinkage vs W/B ratio was a linear function. For Civil engineering concretes, another linear function was found, with a higher slope. These correlations could be explained by the influence of mix-design and the behaviour of recycled concrete aggregates. RCA concrete mixtures actually had higher paste proportions (Table 5), and shrinkage magnitude increases linearly with paste volume [33]. Moreover severe drying is likely to cause drying of RCA [29], [31] whereas they can provide internal curing in sealed conditions [12] or standard drying conditions. Increasing RCA proportion results in an increase in drying shrinkage because of their original paste content and lower modulus. 


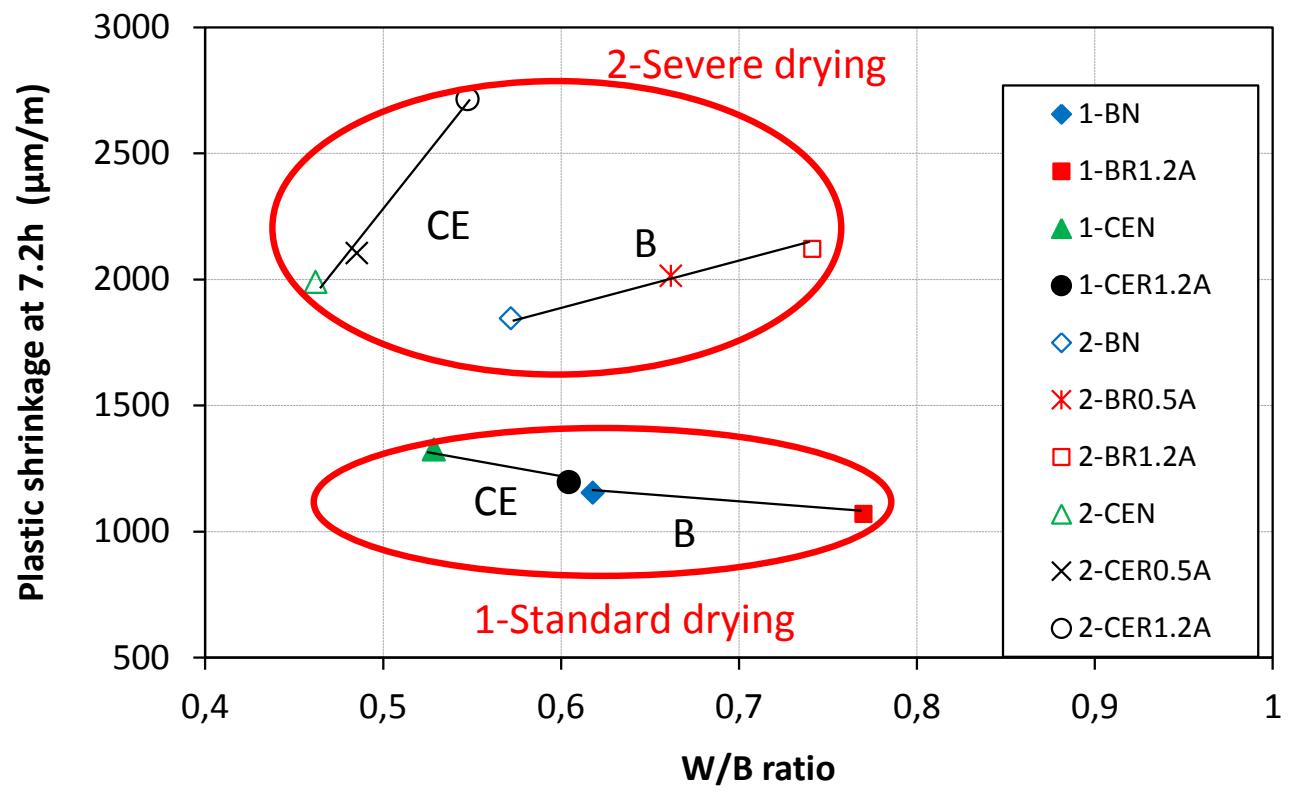

Figure 11. Plastic shrinkage at $7.2 \mathrm{~h}$ and $\mathrm{W} / \mathrm{B}$ ratios

\subsection{Cracking potential of recycled concretes}

The previous sections mainly dealt with shrinkage. In this part, the cracking sensitivity of recycled concretes is analysed. The experimental study was based on the restrained shrinkage mould for fresh concrete to obtain the appearance time of the crack and the crack opening value. The test geometry leads to a cracking in the middle part of the mould where the crack openings are the highest.

Table 9 presents the age of cracking and the crack width (equation 2) at the end of the test $(7.2 \mathrm{~h}$ ). Crack appearance time for $2-\mathrm{BR}_{0.5 \mathrm{~A}}$ and $2-\mathrm{CER}_{1.2 \mathrm{~A}}$ were close. Cracking was delayed by $35-40$ minutes for $2-\mathrm{BR}_{1.2 \mathrm{~A}}$ concrete. An early cracking was observed for $2-\mathrm{CER}_{0.5 \mathrm{~A}}$ concrete. However, cracks observed on recycled concrete with totally saturated aggregates were larger than ones with partially saturated aggregates (Table 9).

Table 9. Cracking time and crack opening values (average value on two tests)

\begin{tabular}{|c|c|c|c|c|}
\hline & $2-\mathrm{BR}_{1.2 \mathrm{~A}}$ & $2-\mathrm{BR}_{0.5 \mathrm{~A}}$ & 2-CER $_{1.2 \mathrm{~A}}$ & 2-CER $0.5 \mathrm{~A}$ \\
\hline Age of cracking $(\mathrm{h})$ & $2.34 \mathrm{~h}$ & $1.70 \mathrm{~h}$ & $1.90 \mathrm{~h}$ & $1.26 \mathrm{~h}$ \\
\hline Crack opening at $7.2 \mathrm{~h}(\mathrm{~mm})$ & 1.02 & 0.83 & 1.22 & 0.92 \\
\hline
\end{tabular}

Figure 12 gives the crack opening as a function of the corresponding shrinkage at 7.2 hours. According to this graph, a global correlation between crack opening and plastic shrinkage value is underlined for recycled concretes. The higher the shrinkage, the larger the crack was. 


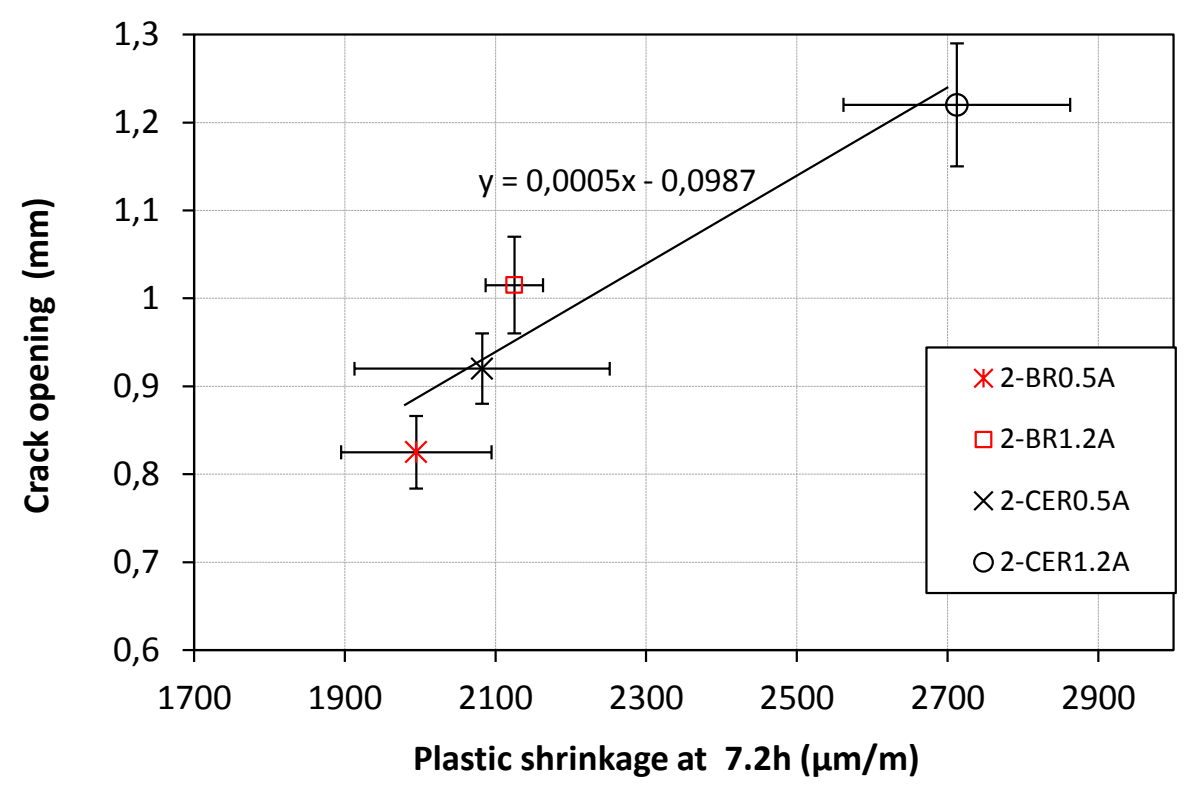

Figure 12. Crack opening over plastic shrinkage value at 7.2h.

For a given initial water saturation of recycled concrete aggregates, Building concretes cracked later than civil engineering concrete (Figure 13). A strong correlation was actually found between the total water introduced in the mixer and the age of cracking. For RCA-based concrete mixtures, the higher the total water content was, the later the cracks appeared.

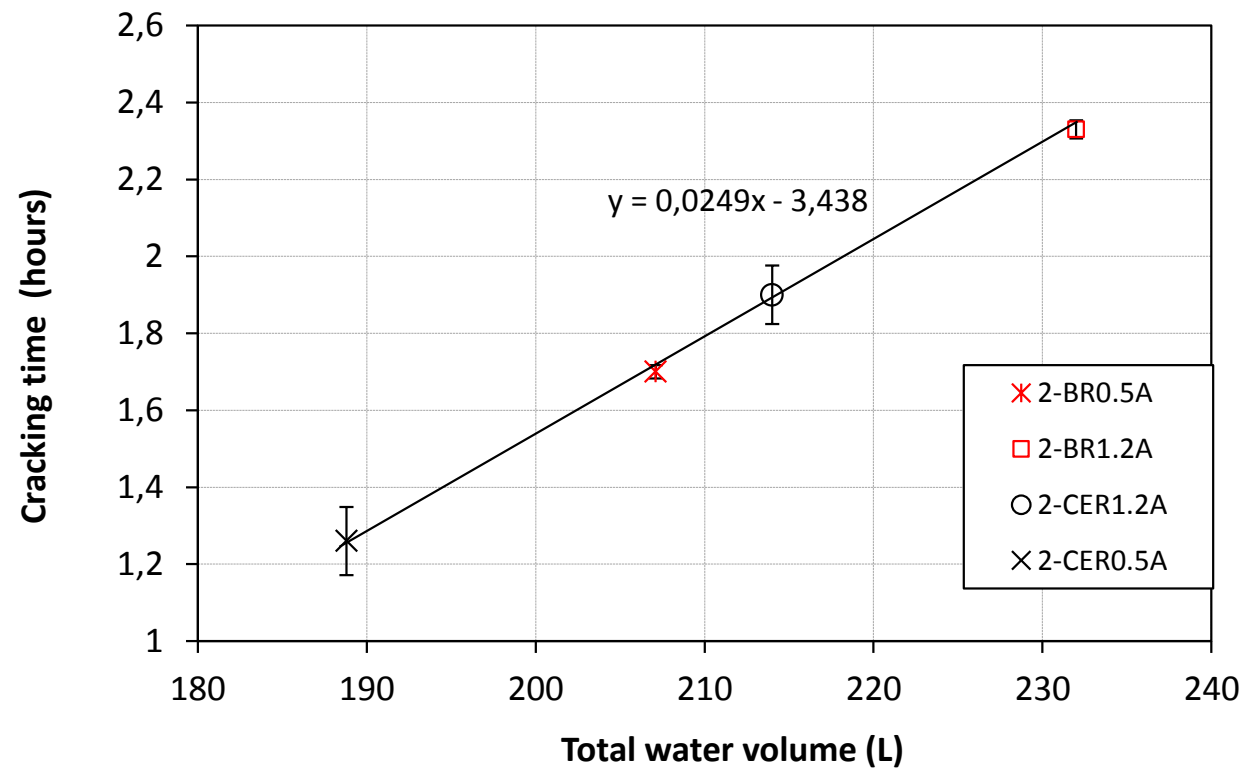

Figure 13. Cracking time over total water volume

The "shrinkage vs W/B ratio" and "cracking time vs total water volume" graphs show that quantity of water and W/B ratio are major parameters. It also shows that the water contained in recycled aggregates influences shrinkage and cracking, whereas usually only the effective water content (water theoretically remaining in cement paste) is considered to be the main parameter in shrinkage development and cracking inception.

As a consequence, water exchanges between recycled aggregates and cement paste occurring under drying should be taken into account. Some authors [13] [15] [25] actually give some evidence of these phenomena. They consider that recycled aggregates can provide internal curing effect for autogenous or drying shrinkage. 


\section{Conclusions}

The study presented in this paper focused on plastic shrinkage of recycled concrete under standard and severe drying conditions and cracking at early-age. Based on the results presented in this paper the flowing conclusions can be drawn:

- $\quad$ The concrete made of recycled concrete aggregates showed significantly higher evaporation rates. This suggests that recycled concrete aggregates were able to provide initially absorbed water.

- $\quad$ All the plastic shrinkage vs. weight loss curves were characterized by three stages. At the second stage plastic shrinkage was a linear function of weight loss. The corresponding coefficient was not significantly influenced by evaporation rate. For a given concrete type (Building or Civil Engineering), the increase in evaporation rate accelerated the development and increased the maximum value of plastic shrinkage.

- $\quad$ The bleeding water on the upper face of the samples protected the concrete and delayed the desiccation. So the shrinkage was lower although the desiccation rate was higher.

- $\quad$ The influence of recycled concrete aggregates (100\% RCA as coarse aggregates) on plastic shrinkage magnitude was found to depend on the evaporation rate. Under standard drying conditions, as the evaporation rate remains relatively low bleeding develops and RCA can provide internal curing and the plastic shrinkage decreases. In severe drying conditions, the drying rate is higher than the internal curing flow and it results in higher shrinkage magnitudes.

- In severe drying conditions the initial water saturation significantly affected the cracking sensitivity of fresh concrete, as added water content was kept constant. The cracking time was delayed when the initial water saturation increased from $50 \%$ to $120 \%$ of nominal absorption. This could be explained by a potential internal curing provided by the initially over-saturated recycled aggregates.

From the experimental analyses performed in this study, it seems possible to design concrete mixtures with recycled concrete coarse aggregates. In sealed conditions or at relatively low evaporation rates, RCA are likely to favor bleeding and provide internal curing, thus a reduction in plastic shrinkage magnitude. However, in severe drying conditions, it is necessary to adapt the curing methods. Moreover, the initial water saturation of RCA should be carefully monitored because it significantly affects the cracking sensitivity of fresh and hardening concrete at high evaporation rates.

\section{Acknowledgments}

Support from the Agence Nationale de la Recherche (National Research Agency, France) within ECOREB project and Projet national (National Project, France) RECYBETON are acknowledged.

\section{References}

[1] PN RECYBETON, RECYclage complet des BETONs, 2011.

[2] D.-T. DAO, (Multi-) recyclage du béton hydraulique. In french, PhD thesis, Ecole Centrale de Nantes, Ecole Centrale de Nantes, 2012.

[3] M. Pepe, A conceptual model to design recycled aggregate concrete for structural applications; $\mathrm{PhD}$ thesis, Universita degli studi di Salerno, Universita degli studi di Salerno, 2014.

[4] R.V. Silva, J. de Brito, R.K. Dhir, Prediction of the shrinkage behavior of recycled aggregate concrete: A review, Construction and Building Materials. 77 (2015) 327-339. doi:10.1016/j.conbuildmat.2014.12.102.

[5] J. Brito, F. Alves, Concrete with recycled aggregates: the Portuguese experimental research, Materials and Structures. 43 (2010) 35-51. doi:10.1617/s11527-010-9595-7.

[6] C.-S. Poon, D. Chan, The use of recycled aggregate in Hong Kong, Resources, Conservation and Recycling. 50 (2006) 293-305.

[7] F.. Wittmann, On the action of capillary pressure in fesh concrete, Cement and Concrete Research. 6 
(1976) 49-56.

[8] S. Zhutovsky, K. Kovler, Effect of internal curing on durability-related properties of high performance concrete, Cement and Concrete Research. 42 (2012) 20-26. doi:10.1016/j.cemconres.2011.07.012.

[9] M.D. Newlands, K.A. Paine, R.K. Dhir, N.A. Vemuri, effect of new generations of concrete on earlyage shrinkage, Dundee, 2008.

[10] A. Domingo-Cabo, C. Lázaro, F. López-Gayarre, M.A. Serrano-López, P. Serna, J.O. CastañoTabares, Creep and shrinkage of recycled aggregate concrete, Construction and Building Materials. 23 (2009) 2545-2553. doi:10.1016/j.conbuildmat.2009.02.018.

[11] R. Cortas, E. Rozière, S. Staquet, a. Hamami, a. Loukili, M.-P. Delplancke-Ogletree, Effect of the water saturation of aggregates on the shrinkage induced cracking risk of concrete at early age, Cement and Concrete Composites. 50 (2014) 1-9. doi:10.1016/j.cemconcomp.2014.02.006.

[12] A. Gonzalez-Corominas, M. Etxeberria, Effects of using recycled concrete aggregates on the shrinkage of high performance concrete, Construction and Building Materials. 115 (2016). doi:10.1016/j.conbuildmat.2016.04.031.

[13] I. Maruyama, R. Sato, A trial of reducing autogenous shrinkage by recycled aggregate, in: D.B. and L.-O.N. B. Persson (Ed.), Proc. Of the 4th International Seminar on Self-Desiccation and Its Importance in Concrete Technology, Lund University, Sweden, 2005: pp. 264-270.

[14] T. Fujiwara, Effect of Aggregate on Drying Shrinkage of Concrete, Journal of Advanced Concrete Technology. 6 (2008) 31-44.

[15] V. Corinaldesi, G. Moriconi, Recycling of rubble from building demolition for low-shrinkage concretes., Waste Management (New York, N.Y.). $30 \quad$ (2010) 655-9. doi:10.1016/j.wasman.2009.11.026.

[16] O.M. Jensen, P.F. Hansen, Autogenous deformation and RH-change in perspective, Cement and Concrete Research. 31 (2001) 1859-1865.

[17] K. Haejin, Crushed returned concrete aggregate in new concrete: characterization, performance, modeling, specification and application. Thèse de doctorat, University of Maryland, 2009.

[18] M. Lalesev, V. Radonjanin, S. Marinkovic, Recycled concrete as aggregate for structural concrete production, Sustainability. 2 (2010) 1204-1225.

[19] M. Bravo, J. de Brito, J. Pontes, L. Evangelista, Durability performance of concrete with recycled aggregates from construction and demolition waste plants, Construction and Building Materials. 77 (2015) 357-369. doi:10.1016/j.conbuildmat.2014.12.103.

[20] M. Gomes, J. Brito, M. Bravo, Structural concrete with incorporation of coarse recycled concrete and ceramic aggregates: durability performance, Materials and Structures. 42 (2009) 663-675. doi:10.1617/s11527-008-9411-9.

[21] L. Ferreira, J. de Brito, M. Barra, Influence of the pre-saturation of recycled coarse concrete aggregates on concrete properties, Magazine of Concrete Research. 63 (2011) 617-627. doi:10.1680/macr.2011.63.8.617.

[22] NF EN 1097-6, NF EN 1097-6 Essais pour déterminer les caractéristiques mécaniques et physiques des granulats - Partie 6 : détermination de la masse volumique et du coefficient d'absorption d'eau, n.d.

[23] NF EN 206/CN 2014, NF EN 206/CN Béton - Spécification ,performance, production et conformité, n.d.

[24] J.-C. Souche, Etude du retrait plastique des bétons à base de granulats recyclés avec mesure de l'influence de leur degré de saturation. In french, PhD Thesis, Université de Montpellier, Ecole des Mines d'Alès, Ecole des Mines d'Alès - Université de Montpellier - Ecole Doctorale I2S Mécanique et Génie civil, 2015.

[25] M. Salgues, J.-C. Souche, P. Devillers, É. Garcia-diaz, Influence of initial saturation degree of recycled aggregates on fresh cement paste characteristics: consequences on recycled concrete 
properties Influence of initial saturation degree of recycled aggregates on fresh cement paste characteristics : conseq, European Journal of Environmental and Civil Engineering. (2016) 1-15.

[26] P. Acker, J.-M. Torrenti, M. Guérinet, La maîtrise de la fissuration au jeûne âge: condition de durabilité des ouvrages en béton, ENPC, 2008.

[27] G.W. Scherer, Theory of Drying, Journal of the American Ceramic Society. 73 (1990) 3-14.

[28] J. Mora-Ruacho, R. Gettu, A. Aguado, Influence of shrinkage-reducing admixtures on the reduction of plastic shrinkage cracking in concrete, Cement and Concrete Research. 39 (2009) 141-146. doi:10.1016/j.cemconres.2008.11.011.

[29] V. Slowik, T. Hübner, M. Schmidt, B. Villmann, Simulation of capillary shrinkage cracking in cement-like materials, Cement and Concrete Composites. 31 (2009) 461-469. doi:10.1016/j.cemconcomp.2009.05.004.

[30] K. Yang, M. Zhong, B. Magee, C. Yang, C. Wang, X. Zhu, Z. Zhang, Investigation of effects of Portland cement fineness and alkali content on concrete plastic shrinkage cracking, Construction and Building Materials. 144 (2017) 279-290. doi:10.1016/j.conbuildmat.2017.03.130.

[31] M. Etxeberria, A. Gonzalez-Corominas, P. Pardo, Influence of seawater and blast furnace cement employment on recycled aggregate concretes' properties, Construction and Building Materials. 115 (2016) 496-505. doi:10.1016/j.conbuildmat.2016.04.064.

[32] P. Turcry, A. Loukili, evaluation of plastic shrinkage cracking of Self-Consolidating Concrete, ACI Materials Journal. 103-M30 (2006) 272-279.

[33] E. Mbemba, Influence du vent et de la cure sur le comportement des bétons au très jeune âge. In french, PhD thesis, Ecole Centrale de Nantes, Ecole centrale de Nantes, 2010.

[34] ACI305R-91, ACI Manual on concrete practice part 2 "Construction practices and inspection pavements," American-Concrete-Institute, 1999.

[35] A. Bendimerad, Impact du degré de saturation des granulats recyclés sur le retrait plastique et le risque de fissuration au jeune âge. In french, PhD Thesis, Ecole centrale de Nantes, Ecole Centrale de Nantes - École Doctorale Sciences Pour l'Ingénieur, Géosciences, Architecture, 2016.

[36] T. Sedran, Mise au point des formules de béton de référence, 2013.

[37] A.Z. Bendimerad, E. Rozière, A. Loukili, Plastic shrinkage and cracking risk of recycled aggregates concrete, Construction and Building Materials. 121 (2016) 733-745. doi:10.1016/j.conbuildmat.2016.06.056.

[38] ASTM C1579, Standard test method for evaluating plastic shrinkage cracking of restrained fiber reinforced concrete, 2006.

[39] A. Leemann, P. Nygaard, P. Lura, Impact of admixtures on the plastic shrinkage cracking of selfcompacting concrete, Cement and Concrete Composites. 46 (2014) 1-7. doi:10.1016/j.cemconcomp.2013.11.002.

[40] A. Leonard, Etude du séchage convectif de boues de station d'épuration. In french, $\mathrm{PhD}$ Thesis, Université de Liège, Université de Liège - faculté des sciences appliquées, 2002.

[41] V. Slowik, M. Schmidt, R. Fritzsch, Cement \& Concrete Composites Capillary pressure in fresh cement-based materials and identification of the air entry value, 30 (2008) 557-565. doi:10.1016/j.cemconcomp.2008.03.002.

[42] commitee 308 ACI 308R01, Guide to Curing Concrete, American-Concrete-Institute, 2001.

[43] P.J. Uno, Plastic shrinkage Cracking and Evaporation Formulas, ACI Materials Journal. 95 (1998) 365-375.

[44] L. Josserand, O. Coussy, F. de Larrard, Bleeding of concrete as an ageing consolidation process, Cement and Concrete Research. 36 (2006) 1603-1608.

[45] A.. Almusallam, M. Maslehuddin, M. Abdul-Waris, M.. Khan, Effect of mix proportions on plastic shrinkage cracking of concrete in hot environments, Construction and Building Materials. 12 (1998) 353-358. doi:10.1016/S0950-0618(98)00019-1. 
[46] M. Wyrzykowski, P. Trtik, B. Munch, J. Weiss, P. Vontobel, P. Lura, Plastic shrinkage of mortars with shrinkage reducing admixture and lightweight aggregates studied by neutron tomography, Cement and Concrete Research. 73 (2015) 238-245. doi:10.1016/j.cemconres.2015.03.013.

[47] Y. Yokoyama, T. Yokoi, J. Ihara, The effects of pore size distribution and working techniques on the absorption and water content of concrete floor slab surfaces, Construction and Building Materials. 50 (2014) 560-566. doi:10.1016/j.conbuildmat.2013.10.013.

[48] K. Haejin, D. Bentz, Internal Curing with Crushed Returned Concrete Aggregates for High Performance Concrete, in: NRMCA Concrete Technology Forum: Concrete Technology Forum: Focus on Sustainable Development, 2008: pp. 1-12.

[49] W. Hansen, J.A. Almudaiheem, Ultimate Drying Shrinkage of Concrete - Influence of major parameters, ACI Materials. 84 (1987) 217-223. 